\title{
Estimating the Probability of Failure and Associated Risk of the California Bay Delta Levee System
}

\author{
Robb Eric S. Moss ${ }^{1}$, Ph.D., P.E., M.ASCE, and J. Michael Eller ${ }^{2}$, S.M.ASCE \\ ${ }^{1}$ Asst. Prof., Dept. Civil and Environmental Engineering, Cal Poly, San Luis \\ Obispo, CA 93407, email: rmoss@ calpoly.edu \\ ${ }^{2}$ Staff Engineer, Curry Group Inc., Redding, CA 96003, email: MikeEller@aol.com
}

\begin{abstract}
Recent events in New Orleans have shown the magnitude of life loss and property damage that can occur due to the failure of man-made levees. The California Bay Delta and Sacramento levee systems in California pose a similar or greater level of risk to life and property. In order to effectively mitigate the hazard associated with levee failure a systematic evaluation of risk must be carried out. This paper presents preliminary research into the risk associated with the California Bay Delta. A comprehensive list of failure modes for man-made levees is presented. Preliminary empirical data on the temporal frequency of failure and the consequences of failure in the Bay Delta has been compiled. Also presented is the frequency of high water conditions, frequency of strong ground shaking, and a discussion of possible correlation of failure with these loading conditions. Based on preliminary empirical data, the distribution of the risk function is estimated using Monte Carlo simulations. The general objectives of this paper are to present an approach to levee risk analysis for the California Bay Delta, stimulate discussion, outline the data gaps that exist, and push for continued research on mitigating this hazard.
\end{abstract}

\section{Introduction}

In engineering, risk is the product of the probability of failure and the consequences of failure (Baecher and Christian, 2003). In order to quantify the risk so that performance-based decisions can be made, both the probability of failure and the consequences of failure must be fully characterized. Failure, as discussed in this paper, means any physical alteration in the levee that subsequently results in flooding. For this particular study the process of quantifying the risk can be lumped into two categories; 1) top-down, and 2) bottom-up. The top-down approach, which is described in this paper, is where existing data on the frequency of levee failures is collected and analyzed. We observe data trends, characterize the data with frequency or probability distributions, and attempt to interpret the results. 
The bottom-up approach is where analytical or physical testing is used to elicit the frequency distribution of different loading conditions and the corresponding levee resistances. An example of an analytical bottom-up approach is the work by Wolff (1996), where probabilistic slope stability analysis is performed on levees and levee systems. We along with colleagues at UCLA are pursuing a bottom-up physical testing approach where derelict levees will be tested to failure using induced ground shaking from an eccentric mass shaker to examine the characteristics of seismic levee resistance and failure.

\section{Failure Mechanisms}

When a levee breaches, the results can be insignificant where a few acres of marsh land are flooded, or catastrophic as seen with some of the New Orleans levee failures. Loading situations that can trigger failures fall into three categories; ground shaking from seismic activity, high water from an increase in runoff and/or high tides, and static stress conditions. From these three loading situations six related failure mechanisms have been observed. These six failure mechanisms were based upon a literature review of levee failure case histories (e.g. USACE, 2006; DWR, 2006a; Seed et al, 2006). These failure mechanisms include; bearing, sliding, slumping/spreading, seepage, erosion, and overtopping. Figure 1 shows a schematic of the loading functions, the failure mechanisms, and how they interrelate.

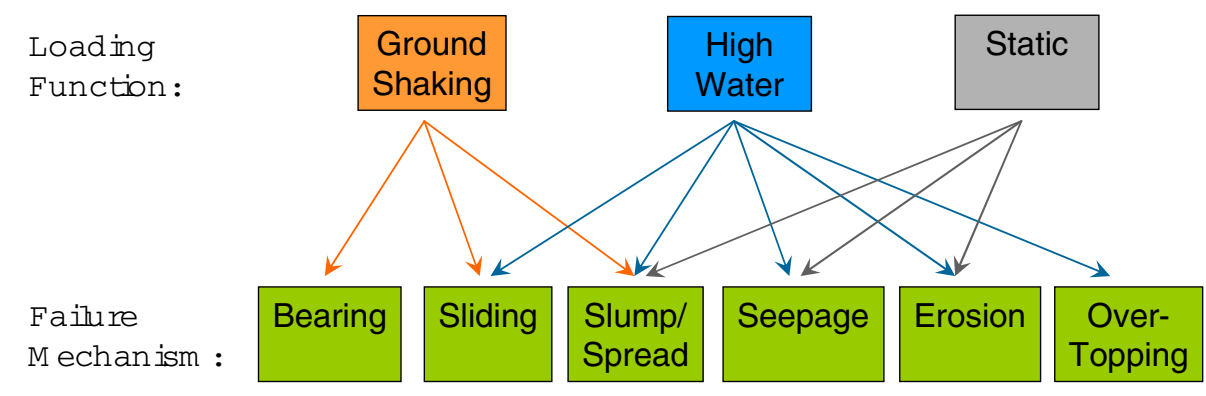

Figure 1. Diagram showing the three loading functions and six failure mechanisms associated with levee failure.

The failure mechanisms have the following characteristics;

- A bearing failure in levees is typically deep-seated and is most likely induced by seismic ground shaking. Failure is commonly triggered by a seismic event that either causes a loss of soil strength or produces destabilizing inertial loading conditions.

- A sliding failure may occur if the foundation soil has a weak or brittle zone resulting in a preferred failure plane. Both seismic induced inertial loading and high water levels can cause sliding failures.

- Slumping and spreading can be generated by two loading conditions. Cyclic loading from earthquakes may generate increased pore pressures and reduced soil strength, leading to volumetric and/or deviatoric strains in the foundation. 
The same results can also occur due to increased pore pressures from high water levels and increased seepage.

- Seepage is one of the most common failure mechanisms in levees. Levees are built in fluvial depositional environments and it is common to find levees with an existing sandy layer beneath the foundation. The sandy layer can be a conduit for flow underneath the levee, resulting in critical conditions at the inboard (or landside) toe. This leads to erosion of the foundation during a high storm or a consistent weakening of the foundation over a long period of time, both eventually leading to failure. Biogenic agents can also lead to destabilizing seepage. This can include rodent holes, tree roots, or other biological activity that create conduits for seepage.

- High velocity flows can erode material from the outboard or waterside of the levee, which may lead to instability and failure. Erosion can occur at once or over time as a function of the storm cycle and the scale of the peak storms.

- The failure mechanism of overtopping occurs when high water exceeds the elevation of the levee crest. The water energy is then concentrated at the inboard toe of the levee leading to soil erosion and decreased levee stability. Overtopping failure can be exacerbated by decreased levee crest height due to land subsidence.

Compounding these failure mechanisms, investigation of the New Orleans levee failures (Seed et al., 2006) found that many failures were due to design inconsistencies. Areas where crest heights of two adjoining levees differ or where there is an opening or "weak spot" in a levee are prime locations for seepage, overtopping, and erosion to occur.

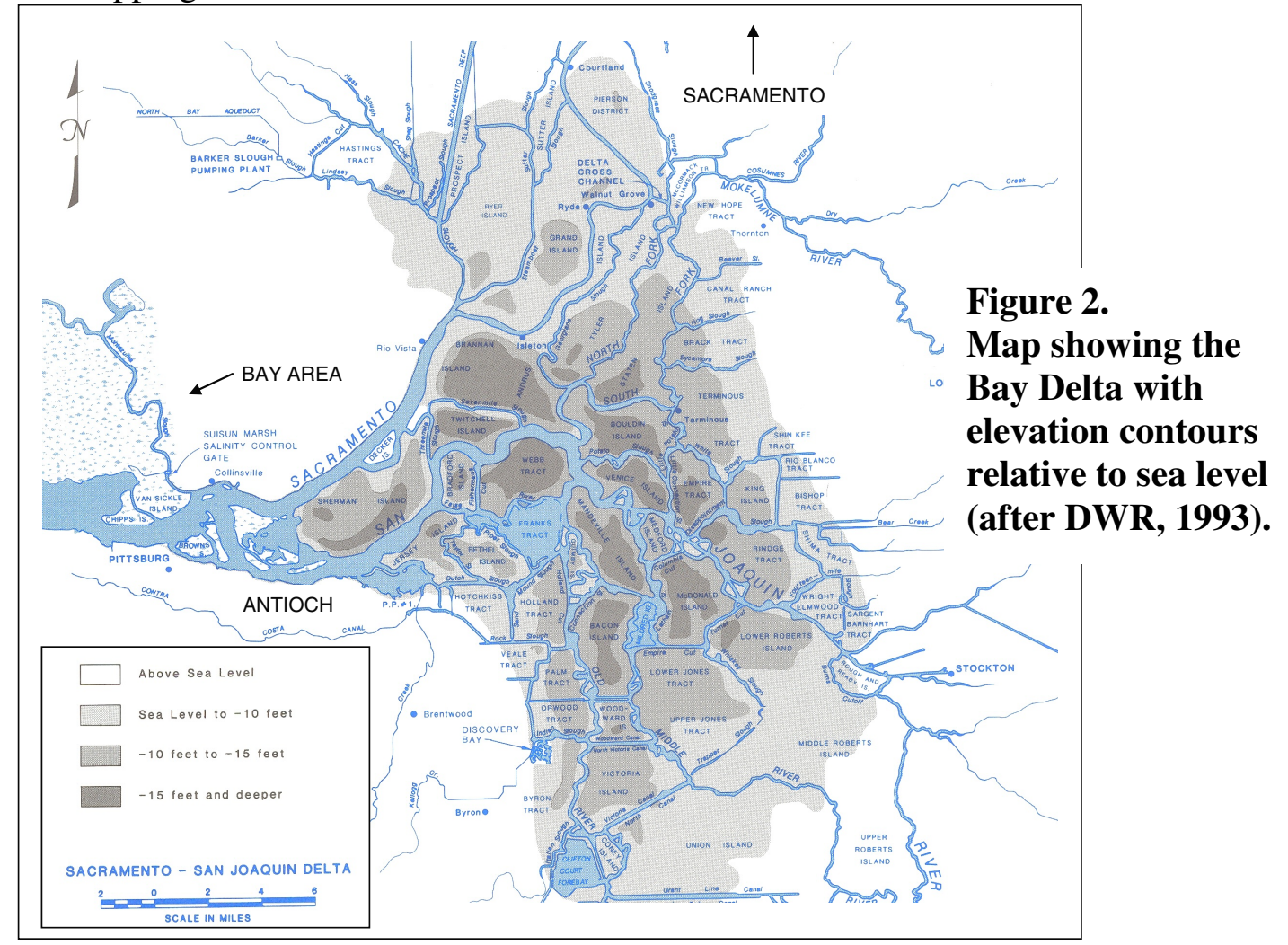


Figure 2 shows a map of the Bay Delta. The relative elevation with respect to sea level is shown as shaded contours. In the Bay Delta levee system, because of subsidence and loss of soil through wind erosion the majority of the land protected by the levees is at or below sea level. Therefore a failure via any failure mechanism results in flooding.

\section{Empirical data}

There is paucity of useable empirical data documenting levee failures within the Bay Delta. This paper presents the initial findings of a data search for useable failure, consequences, and loading information.

\section{Levee Failures}

For this preliminary analysis we collected data from the California Department of Water Resources (DWR, 2006a; DWR Public Affairs Chief Ted Thomas, personal communication) and the U.S. Army Corp of Engineers (USACE, 2006) to compile a list of the annual number of levee failures from 1900 to the present. This list unfortunately does not include the mechanism of the failure but does provide us with a temporal measure of levee failure occurrence. Figure 3 shows a histogram of the number of failures per year. Based on this data we observe a mean annual rate of levee failure of 1.5 with a sample standard deviation of 3.4.

One discrepancy in this database is that it does not account for the variability of the levees in both time and space. The levees that were built around the turn of the last century were little more than mounds of dirt heaped upon the existing natural levees, whereas today we ensure that there is at least a minimal amount of engineering that goes into new levee design and construction. With time more levees have been built, resulting in a larger overall number of levees that could potentially fail. These two temporal issues result in contradictory effects on the number of observed failures.

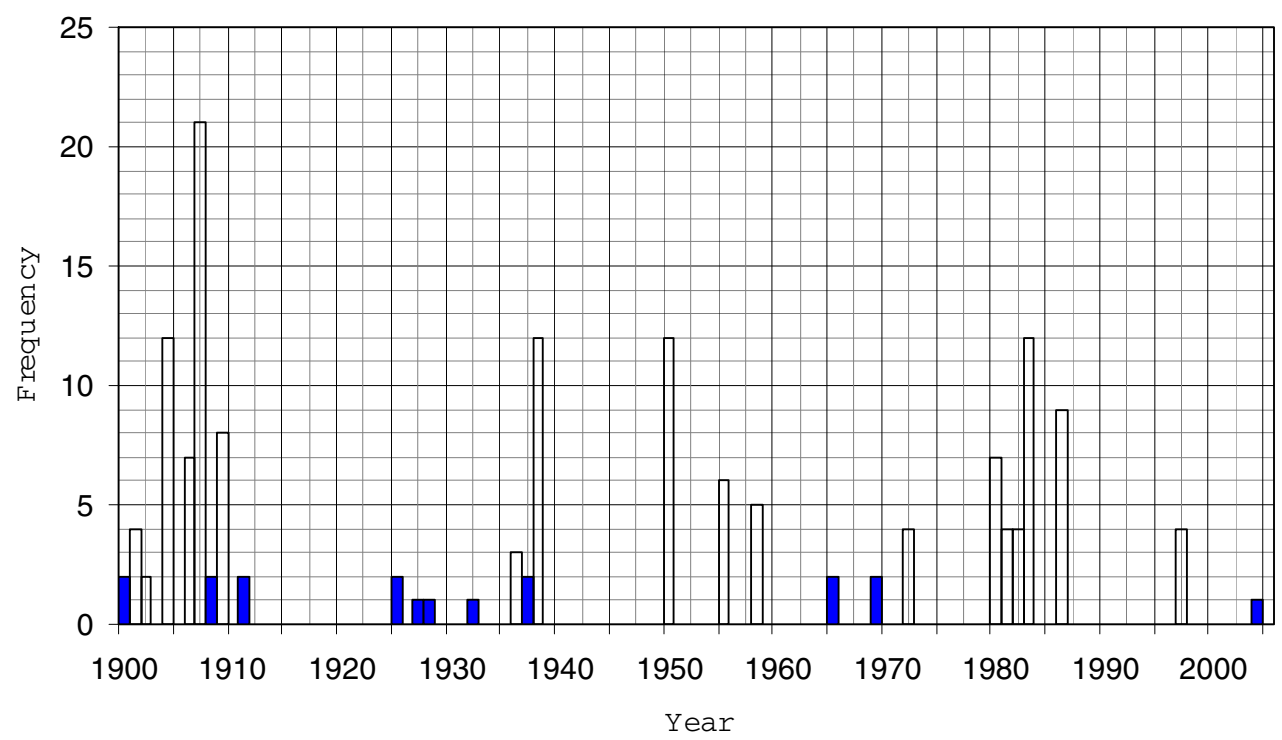

Figure 3. Histogram of the frequency of Bay Delta levee failures with time, from 1900 to the present. 
Spatially the depositional environment of the foundation material in the upper reaches of the Delta is much different than in the lower reaches of the Delta.

Heterogeneity of foundation and levee soils vary on many different scales from Delta wide variations to small local variations. The current data set is lumped together and therefore gives us a coarse evaluation, neglecting site specific and regional conditions. Ultimately we would like to account for these effects in future research.

\section{Consequences}

Along with the frequency of failure data we also collected data on the area of land flooded by the failures. This data is biased in that for a specific levee (Andrus Island levee for example) a fixed area of land will be flooded upon each failure (29 $\mathrm{km}^{2}$ ) because it is an island that is below the mean water level and will fill up following every breach. Nonetheless the area flooded with each failure, aggregated for all the levees in the Delta, provides a crude measure of the consequences per failure. Figure 4 shows a histogram of the area flooded per failure (note: 100 acres = $\left.4.05 \mathrm{~km}^{2}\right)$. The mean or average area flooded per levee failure is $14.1 \mathrm{~km}^{2}$, with a sample standard deviation of $11.2 \mathrm{~km}^{2}$. This information defines the consequences for the levee failures.

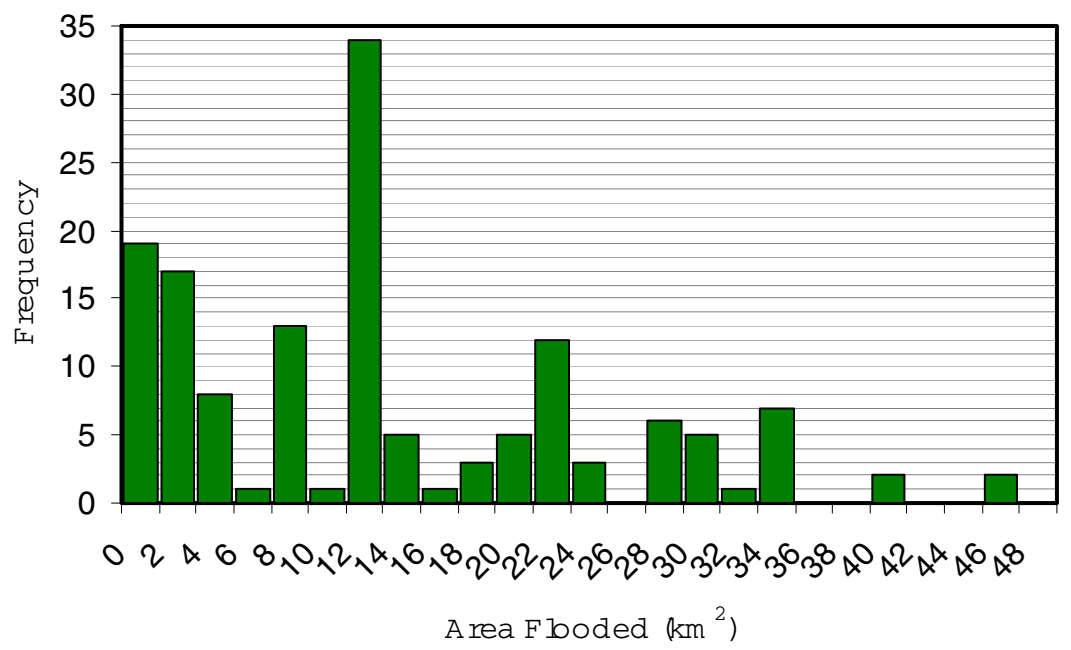

Figure 4. Histogram showing the frequency of land flooded per failure for the failures from 1901 to the present.

\section{Ground Shaking}

Although the CALFED (2000) report on the seismic vulnerability of the Delta levees reported "historical information indicates that there has been little damage to Delta levees caused by earthquakes," for completeness we have investigated the possibility further. A search of historical earthquakes within $100 \mathrm{~km}$ of the centroid of the Delta results in a short list of seismic events. Of those, the only viable events, or events strong enough to have the potential for ground shaking within the Delta are the 1906 San Francisco earthquake (M7.8) and the 1980 Livermore earthquake (M5.8). The epicenters were located approximately 94 and $32 \mathrm{~km}$ from the centroid of the Delta, respectively. 
Using the strong ground motion attenuation relationship by Sadigh et al. (1997), which tends to provide a reasonable median estimate with respect to other common Western U.S. attenuation relationships, the peak rock accelerations are estimated to range from 0.05 at the centroid to 0.12 at the closest levee to the epicenters. These values represent an estimate of the ground motion at depth at a soil/rock boundary corresponding to a shear wave velocity of $760 \mathrm{~m} / \mathrm{sec}$, the NEHRP B/C site class boundary. To propagate the motion upwards from the soil/rock boundary to the surface, the effects of the deep soft Delta sediments need to be taken into account. The CALFED (2000) seismic vulnerability sub-team used a simplified approach, applying a single amplification factor of 1.6 to approximate the soft soil response. If we use the same approach this results in an upper bound median value of $0.2 \mathrm{~g}$ for surface ground accelerations.

Inspection of the failure histogram shows a high frequency and a clustering of levee failures following the years 1906 and 1980. Further investigation into existing records is needed to show causation and not just a loose correlation of seismic activity and levee failure.

\section{High Water}

High water levels for the Delta levee system is a difficult parameter to measure. The water ways and sloughs in the Delta extend over $1000 \mathrm{~km}$. The water level at any time against a levee within the Delta is influenced by; 1) the input of three rivers from the north, east, and south, 2) the tidal fluctuations of the Pacific Ocean from the west, and 3) water engineering features that modify flow within the system (Simi and Ruhl, 2005).

For a failure analysis we are generally interested in extreme events that result in peak loading conditions. A cursory analysis of the high water loading conditions was performed for this study looking at the peak stage (or peak water surface elevation). The Antioch Station (B9502), location shown on Figure 2, was used as the indicator of high water conditions throughout the Delta because; it lies near the confluence of the rivers, is sufficiently downstream to experience full tidal effects, has a similar elevation as other low lying areas in the delta, and presented the most complete dataset available at the time of data collection (DWR, 2006b).

Figure 5 shows the peak annual stage for each year. As can be seen in the plot the Antioch Station recorded relatively high water years in 1986, 1998, and 2006. Generally the peak high water was observed in or around January 1 which corresponds to the highest expected tides, and in the months of December through February which corresponds to the highest rainfall runoff, although there were some exceptions. This winter trend may be a good indicator to use when back-analyzing failure case histories. If the failure did not occur in the time frame of December through January, then one can check stage records around the Delta to determine if it was a high run-off year. If not then the failure loading can be attributed to something other than high water.

At this time we do not have any evidence that high water was the cause of the documented levee failures. We can only show crude correlation as with the seismic data. It can be observed that the high flows in 1986 correspond with a rash of levee failures in the same year; 9 reported for that year as shown on Figure 2. The high flows in 1998 do not have the same corresponding frequency of failures, but the peak 
annual stage in 1997 is close to the level in 1986 and we see a number of failures reported for 1997. If the weak levees had already failed due to the high flows in 1997 then there may have been few left to fail with the slightly higher flows in 1998. Again, this interpretation is strictly correlative and further investigations into the failure records needs to be performed to show causation.

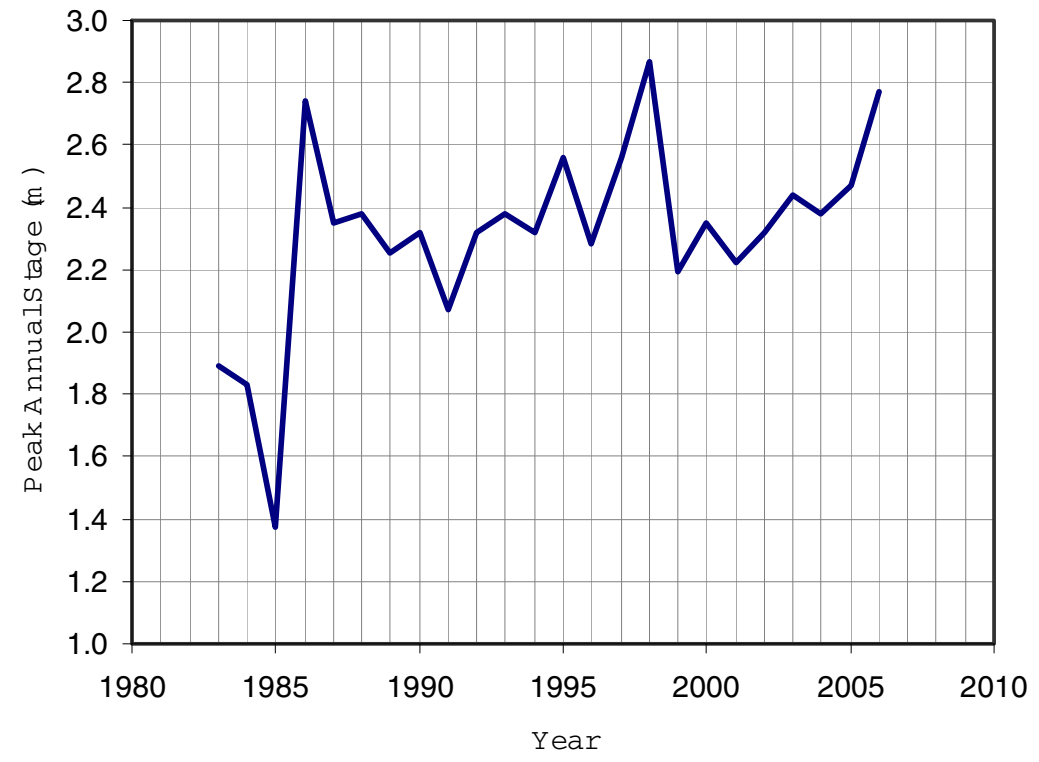

Figure 5. Plot of the peak annual stage at the Antioch Station for the years 1983 to the present.

Another effect that needs to be investigated is the occurrence of rapid water level drawdown and the potential for this to destabilize levees. Conceptually this is possible, but it is unknown if this has been observed and if there exists stage data with sufficient resolution to measure a rapid decrease in the water level.

\section{Risk Analysis}

Risk in an engineering context is the product of the probability of failure and the consequences of that failure (Baecher and Christian, 2003). The data collected so far provides a coarse measure of the probability of failure and the consequences of failure for the California Bay Delta. Although it would be more useful to have the consequences in terms of dollar figures or loss of life, at this stage in the research we have information on area of land flooded with future goals of tying this to dollar figures and life risk. To provide a performance-based measure of the risk we model the probability of failure and consequences as random variables and then perform Monte Carlo simulations to model the distribution of the product.

The annual probability of failure can be modeled as a discrete random variable using the statistics of failure frequency as described previously. We assume that each levee failure represents an independent event in space and time and use the negative binomial distribution (Ang and Tang, 2007) to model the number of discrete levee failures in a given time frame. By inspection the negative binomial distribution provides a reasonable fit to the data, with a $\mu=1.2$ and a $\sigma=3.0$ which compares to the sample mean of 1.5 and sample standard deviation of 3.4. This distribution was truncated at 21 failures, the maximum reported number of annual failures. 
The consequences of a levee failure can be modeled using a shifted gamma distribution (Ang and Tang, 2007) that approximates the limited data set. By inspection the shifted gamma distribution provides a reasonable fit to the data, with a $\mu=16.0$ and $\sigma=12.6$ which compares to the sample mean of 14.1 and sample standard deviation of 11.2.

A Monte Carlo simulation sampled from both distributions, and the product is an estimate of the risk distribution. We randomly generated the annual number of levee failures following the negative binomial distribution, calculated the probability of this number of failures in any given year, and then randomly generated the flooded area per failure following the shifted Gamma distribution. The result is the frequency distribution of the annual amount of land flooded due to levee failures in the Delta. The number of simulations was increased until the risk distribution produced consistent results and the average or expected value stabilized. The following equation describes the process for a single simulation,

$$
R_{i}=p\left(f_{i}\right) \cdot \sum_{n} c_{n}
$$

where $R_{i}$ is the ith simulation of the risk function, $p\left(f_{i}\right)$ is the $i^{\text {th }}$ probability of $n$ number of randomly generated annual failures, and $c_{n}$ is the randomly generated consequences for each failure summed up for $n$ number of annual failures. The result (Figure 6) is a distribution showing the annual frequency of $\mathrm{km}^{2}$ flooded. This risk distribution indicates that the average or expected annual amount of land flooded due to levee failure, irrespective of the failure mechanism, is on the order of $8.54 \mathrm{~km}^{2}$. The risk distribution exhibits an exponentially decreasing function indicating that there is a much higher frequency of little or no flooding than large catastrophic events.

If economic figures were applied to this risk function then we could calculate the annual expected value of economic loss. This would involve coming up with the spatial distribution of different economic bins for land valuation (e.g. agricultural land versus housing subdivisions). The risk could then be used as input in a decision tree, representing the different economic bins and the potential for annual losses presented in dollar figures. This decision tree could also be expanded to account for the potential for life loss due to levee failure.

\section{Future Research}

The next step in this top-down approach of quantifying the risk of levee failure in the Bay Delta is to parse the risk distribution into fractions by loading function. First we need to acquire better documentation of the nature of failure for each of the reported failures, and then corroborate these failure mechanisms with the loading functions. Peak high water data that extends back further than 1983 would be particularly useful in determining the correlation with levee failures.

After the data has been plumbed for its usefulness we can then perform comparative analytical modeling to determine the most likely cause of failure for a given levee cross-section and levee condition. Performing this for several representative levee cross-sections would provide us with a relative measure of priority in loading conditions and failure mechanisms. 

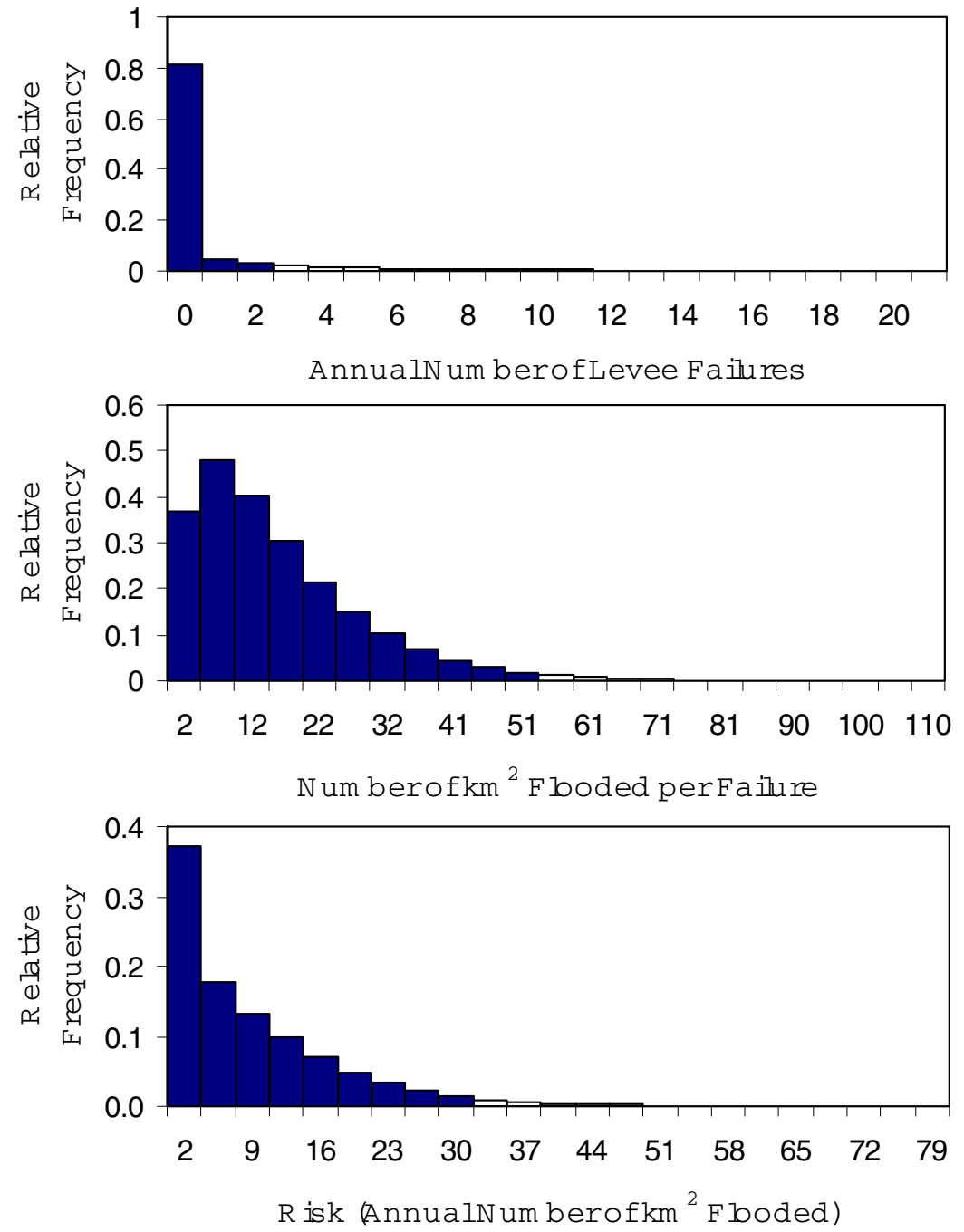

Figure 6. Results of $10^{6}$ Monte Carlo simulations for the distributions of the annual number of failures, land flooded per failure, and the annual risk.

As the data and analyses become more refined we can represent the Bay Delta and associated risk in a GIS based format to account for spatial variability of loading, resistance, and consequences. Ultimately this is the goal, to have a map showing gradations of loading, resistance, relative risk of each levee reach, and the consequences of a specific levee failure. This would allow decision-makers to focus efforts on the most susceptible and potentially costly levee failures in a systematic manner.

\section{Summary}

This paper presents preliminary analysis of the risk associated with the California Bay Delta levee system. A conceptual framework of levee failure was outlined. A preliminary database was collected and processed for use in a risk-based format. Frequency distributions were fit to the data and then Monte Carlo simulations were used to sample the distributions and estimate the risk function. The results are 
presented as the annual probability distribution of levee failure, the distribution of consequences or land flooded per levee failure, and the risk distribution of annual land flooded in the Delta. The authors hope to stimulate discussion of risk in the Delta, identify gaps in the existing data, and push for more research to help mitigate the hazard associated with levee failures in California and elsewhere.

\section{References}

Ang, A. H-S. and Tang, W. H. (2007). Probability Concepts in Engineering, $2^{\text {nd }}$ Ed. J. Wiley, New York.

Baecher, G.B. and Christian, J.T. (2003). Reliability and Statistics in Geotechnical Engineering. John Wiley and Sons, Inc.

CALFED (2000). "Seismic vulnerability of the Sacramento-San Joaquin Delta Levees." Bay-Delta program, seismic vulnerability sub-team, April.

DWR (1993). Sacramento San Joaquin Delta Atlas. Department of Water Resources, Sacramento.

DWR (2006a). Levee Repairs. May 25. www.levees.water.ca.gov

DWR (2006b) Stage gauge information for CA DWR stations. http://www.gic.csuchico.edu/projects/watersheds/delta/

Sadigh, K., Chang, C.-Y., Egan, J. A., Makdisi, F., and Youngs, R. R. (1997). "Attenuation Relationships for Shallow Crustal Earthquakes Based on California Strong Motion Data." Seismological Research Letters, 68(1), 180189.

Seed, R. B., Abdelmalak, R. E., Athanasopoulos, A. G., Bea, R. G., Boutwell, G. P., Bray, J. D., Briaud, J.-L., Cheung, C., Cobos-Roa, D., Cohen-Waeber, J., Collins, B. D., Ehrensing, L., Farber, D., Hannenmann, M., Harder, L. F., Inamine, M. S., Inkabi, K. S., Kammerer, A. M., Karadeniz, D., Kayen, R. E., Moss, R. E. S., Nicks, J., Nimala, S., Pestana, J. M., Porter, J., Rhee, K., Riemer, M. F., Roberts, K., Rogers, J. D., Storesund, R., Thompson, A., Govindasamy, A. V., Vera-Grunauer, X., Wartman, J., Watkins, C. M., Wenk, E., and Yim, S. (2006). "Investigation of the Performance of the New Orleans Flood Protection Systems in Hurricane Katrina on August 29, 2005." NSF Independent Levee Investigation Team, Draft Final Report, Report No. UCB/CCRM-06/01, May 22. www.ce.berkeley.edu/ new_orleans/report

Simi, J. and Ruhl, C. (2005) "Summary of Delta Hydrology Data Water Years 19852004." $\quad$ http://science.calwater.ca.gov/pdf/workshops/POD/CDFG_POD_ Delta_hydrology_summary_1985-2004.pdf

USACE (2006) "Sacramento - San Joaquin Delta Report to Congress." 18 May. http://www.spk.usace.army.mil/organizations/cespk-pao/delta/report.html

Wolff, T. F. (1996). "Probabilistic Slope Stability in Theory and Practice." Uncertainty '96, 419-433. 